\title{
ENVIRONMENTAL EDUCATION DEVELOPMENT IN MALTA: A CONTEXTUAL STUDY OF THE EVENTS THAT HAVE SHAPED THE DEVELOPMENT OF ENVIRONMENTAL EDUCATION IN MALTA
}

\author{
Mark Mifsud \\ University of Malta, Malta
}

\begin{abstract}
This paper discusses the historic development of environmental education in Malta and identifies environmental non-governmental organisations as the main promoters of environmental education in Malta. Environmental awareness started to increase as a response to major environmental issues on the island, but was a long affair, hindered in its development by a number of factors, including the governments' non-committal policy, the colonial mentality and the highly competitive educational system. European Union accession had a positive impact on the development mainly due to the imposed requirements. Subsequent governments have realised the importance of environmental education as an effective solution to ensure environmental sustainability. Nonetheless, as environmental education goals take a long time to be achieved, the lack of short-term achievements may be somewhat hindering its development. A context-based environmental education development model was designed to illustrate the complex relations identified in the study. The study suggests a commitment towards locally produced materials, genuine environmental non-governmental organisations and funding up of a co-ordinating centre for the promotion of environmental education at all academic levels.
\end{abstract}

Key words: historical events, sustainable development, environmental education

\section{Introduction}

Small islands tend to be very vulnerable to environmental degradation, as people strive for a better quality of life by focusing on improving their social and economic conditions and disregarding the environment (Ventura, 1994). Environmental degradation is very apparent in small islands like Malta mostly due to the lack of space and resources and also due to the pressures exerted by a population which tends to be in a process of development. Sustainable development is crucial for all countries and, even more so, in small islands like Malta due to the limited resource base and high population density. 


\section{The beginnings: Environmental education (EE) and local non-governmental organisa- tions (NGOs)}

The first response to a global effort to improve the environment came from various NGOs, including Nature Trust and Birdlife. These NGOs organised activities, such as campaigns and seminars, and published leaflets, magazines and articles in newspapers to increase public awareness (Pace, 1995). The beginnings of EE in the Maltese islands can also be traced back to NGOs. The first two environmental NGOs (The Maltese Ornithological Society and the Society for the Study and Conservation of Nature) were set up in 1962. Human persecution of particular species is a common occurrence in the islands. Bird shooting and trapping are common pastimes for a number of Maltese males, while children capture tadpoles, frogs, chameleons and hedgehogs from the countryside. In response to these activities, a number of interested individuals (mostly biology and science teachers) came together and set up the first local environmental NGOs with the main aim of increasing public awareness about particular species which have been persecuted locally.

The governments' commitment towards the environment improved consistently after the island applied for the European Union (EU) membership in 1990. The Environmental Protection Act (one of the first environmental laws of the country) was passed in 1992. Eventually, a number of other laws were passed, but the government lost the election in 1996, and the bird hunting laws were again watered down by the opposition.

Nonetheless, Malta eventually became a full EU member on 1 May 2004, after a very close referendum. The country has now adopted the majority of the EU environmental laws although it has a special number of derogations due to its particular geography. A derogation means that Malta would not apply a law or part of it. For instance, under the EU law, hunting in spring is normally prohibited so that birds can be protected during migration. In Malta, the two main species that are hunted are turtledoves and quails. Malta will continue to allow hunting for these two species in spring.

NGOs have now become very active in the formal sector and organise environmental campaigns aimed at school children. They also supply teaching resources and promotional material to the schools and teachers. Some NGOs have even organised courses for teachers to equip them with the skills required to organise EE activities.

\section{Formal education: An introduction}

Malta's state school sector is influenced, to a large extent, by the British educational system, owing to its colonial past. The educational system is divided into three main sections:

- $\quad$ primary education (from age five to eleven);

- secondary education (from age eleven to sixteen);

- $\quad$ tertiary education (16+).

Schooling is compulsory from age 5 to 16 and kindergarten classes are provided from the age of free. In the primary and secondary sectors, there are state, church and private schools. 
About 30\% of all students attend the non-state sector schools (Sultana, 1995). Church schools are substantially subsidised by the government, and the tuition is free. Malta used to rely on English based GCEs ordinary levels and advanced levels, but, eventually, a national system called Matriculation Secondary Education Certificate (MATSEC) came into place in 1992 and replaced the English examinations. The MATSEC system includes Ordinary levels and Advanced levels, and a new level in between the two termed the Intermediate level. Nevertheless, a large number of resources in schools, such as textbooks, are still British-based. After two years, students sit for 'Matriculation' MATSEC examinations at intermediate and advanced levels at the sixth form. The MATSEC examinations enable successful students to move on to tertiary education.

Key features of the Maltese educational system which may have an effect on the provision of EE include:

1. an overwhelming reliance on the United Kingdom for educational models, textbooks and expertise (Sultana, 1999);

2. a centralised state education system that is constrained by bureaucracy and practices, such as the appointment to positions of responsibility on the basis of seniority and not on qualifications and merit (Darmanin, 1990; Wain, 1991; Farrugia, 1992; Fenech, 1994);

3. a private school system, consisting of independent and church schools that cater for approximately $30 \%$ of the total students' population and that have intensified intra and inter school streaming (Sultana, 1995), increased the culture of competitive achievement (Wain, 1995), and that direct the best human and material resources to the best achievers rather than to those most in need (Mifsud, 1993).

\section{Formal education: Colonial issues}

In the eighties, the formal education sector started to give some importance to the study of the environment and other conservation issues. Nevertheless, the development in this direction was hindered, particularly due to our colonial past. Malta's strategic position in the Mediterranean, in between Europe and Africa, made it a perfect stronghold for consecutive colonisers. Malta was colonised by the Phoenicians, the Romans, the Arabs, the Angevins, the Aragonese, the Knights of Saint John and the British. The country gained its independence from the United Kingdom in 1964, and, in 1974, it became a republic with its own president.

The Maltese people seem to have a problem, realising they own the island itself and, therefore, its environment. Maltese homes are kept flawlessly clean, but, in the outside, the environment trash can be found everywhere. The Maltese native language is thought and understood by everyone, but English speaking is still considered to be upper class. Boissevain (1990), who has studied the Maltese social culture for over forty years, argues that generally the Maltese believe that, if something is foreign, it is better. The Maltese manifest pride in their homes, but not in their land or language. In Malta, it is usually held that the views of persons who occupy superior positions should not be questioned (Boissevain, 1990). This tradition is still thriving 
nowadays, and some Maltese people do not answer or challenge their superiors. One reason is that one day these same superiors will be interviewing the children of their employees for a job.

Tied with the colonial past issue is the problem of transferability of practice. Good practice in one country does not imply that it will be positively transferred to another country with equally encouraging results. The whole Maltese educational system and textbooks have been adopted and transferred from our last colonisers, and our system still shows the vestiges of the British educational system.

\section{EE at primary level}

In 1982, nature studies, geography, history and civics were put together under the title of social studies in order to provide some form of EE over the last four years of the primary period (Ventura, 1993). At primary level, pupils are expected to achieve good formation in character and scientific knowledge in the environmental field, so that they realise that they should appreciate and safeguard our habitat (Ministry of Education, 1989).

Nevertheless, it seems difficult to achieve any form of success with EE programmes in the Maltese islands (Ventura, 1994). This is owing to a number of reasons, including the lack of teacher preparation, the lack of resources, intense streaming and selective examinations that exclude the non-examinable components of the curriculum (Ventura, 1994). Not much progress has been registered in this regard; unpublished research (Mifsud, 2004) shows that most EE programmes in Malta are hindered by the same reasons prevalent in the 1994 study. Some of these constraints have also been reported by other studies (Ham \& Sewing, 1987; Samuel, 1993; Sussman, 1999).

There were three main projects that furthered EE in primary schools in Malta in the early nineties. First, there was a UNESCO funded Environmental Education Programme (EEP) run by the Faculty of Education of the University of Malta. The EEP aimed at producing a teacher's manual with practical suggestions on how to infuse EE into primary school subjects as a cross-curricular theme to bring about social change. The project was reasonably successful in generating a new approach to EE in schools based on interdisciplinarity. EE was not presented as a subject, but as a process to be infused in all curricular subjects, and it is still viewed as a cross-curricular theme nowadays. In 1993, the Science Centre of the Education Division inaugurated the second initiative by publishing its teacher's manual on the implementation of $\mathrm{EE}$ in the curriculum. The publication was distributed to all teachers with the intention that they would implement its suggestions in their schemes of work, but no monitoring and evaluation of the implementation were initiated, mainly due to lack of funding. The third project was an NGO initiative called 'Dinja Wahda' (One World) which was run by Birdlife, Malta. It is an award scheme, involving 14 different activities, and was accepted and adopted by more than $50 \%$ of the Maltese primary schools (Grima, 1996). The first edition of Dinja Wahda was carried out in the school year 1994-1995. Since then, there were subsequent editions in the school years 1999/2000, 2001/2002, 2003/2004 and 2005/2006. The intrinsic value of Dinja 
Wahda is in its environmental message. However, the initiative also carries a competitive element where schools earn points for every activity they accomplish, and it must be noted that in some schools this has become the overriding aim of Dinja Wahda.

One of the latest EE developments in the primary sector is the initiation of the EkoSkola (Local Eco-School initiative) programme. It is an innovative programme in Malta, as it involves collaboration between an NGO (Nature Trust) and the government. This is an international EE programme in which about three million children from about 13 thousand schools located in 33 different countries participate. The programme encourages the participation of children in decision-making, planning and implementation of environmental activities with the aim of improving the quality of life in their school and community. The EkoSkola programme was developed in 1994 by the Foundation for Environmental Education (FEE) and seeks to raise environmental awareness and to promote sustainable development at a local level in the classroom and, in the wider community, through the implementation of the United Nations' Local Agenda 21. Nature Trust (Malta), in collaboration with the government, introduced the programme in Malta in 2002 as a pilot project.

From what has been achieved up to now, it seems that EkoSkola is encouraging the holistic development of Maltese schools and opening up innovative collaborative strategies with Local Councils (Mifsud, 2004). Nonetheless, through personal observation as a teaching practice tutor, I have noted that some schools seem to be more interested in gaining points for certification rather than raising the intrinsic value of environmental stewardship in the whole school community.

\section{EE at secondary level}

The present curriculum, published in 1999, has been a step in the right direction with the inclusion of environmental studies at secondary level ('O' level). This non-compulsory subject includes sections on management of resources, ecosystems, human population, pollution, climate and geology. One concern brought about by this subject is that it takes a local viewpoint to global problems and solutions. A second concern is that the subject is now examinable. Parents are, now, seeing the subject as important not due to value development, but as it can add a certificate to their children's already long list. The dominant educational ideology sees the school as preparing youth for a job to work, and certification, therefore, is highly regarded from a very early age. Environmental studies are included in a central part of the secondary level curriculum which is common to all schools and through all stages at this level (Ministry of Education, 1990). Therefore, students use this subject to gain another qualification simply by memorising facts, as it is considered to be a 'soft' option. In fact, $94.8 \%$ of those opting for environmental studies got a passmark in 2007 (MATSEC, 2008a).

Opportunities to infuse EE into other subjects at secondary school, especially the sciences, but it is up to the individual teacher to carry them out. Integrated science exposes students to issues of waste management, renewable energy, pollution and biodiversity. All these topics are treated in more detail, at a later stage, in their respective subjects, such as biology, chem- 
istry and physics. The incorporation of environmental issues in the science curriculum can increase the relevance of science to students (Brody, 1994).

$\mathrm{EE}$ can be infused into the rest of the curriculum to expose students to an array of environmental issues. Numerical problems in mathematics can utilise environmental statistics and trends, while essays in languages can cover current environmental issues. The opportunities are there, and the new curriculum proposes measures, such as interdisciplinarity, the development of critical thinking, participatory skills and a learner-oriented pedagogy (Ministry of Education, 1999). Nonetheless, consultation with schools and teachers mainly occurred after the first version of the curriculum was drafted by government officials and university lecturers. This factor, probably, reduces the relevance and sense of ownership of the curriculum on the teachers' part. It is up to the individual teachers to make the difficult decision to include EE or not, bearing in mind the considerable stress caused by the still prevalent examination mentality and lack of timetable time.

\section{EE at post-secondary level}

The post-secondary curriculum emphasises that education, at this level, should instil a sense of responsibility towards the environment. Students are also expected to achieve environmental awareness, which is respect for one's common habitat on whose well-being our very existence depends (Ministry of Education, 1991). During 1989, the University of Malta introduced "Systems of Knowledge" - an intermediate examinable subject intended to broaden the traditional disciplines that youth study for their advanced levels. This is an obligatory entry requirement for all undergraduate courses at the University of Malta. The syllabus comprises a number of study areas, including one concerning the environment. This part discusses some concepts of the quality of life and the environment, the basis of pro-environmental action and the principles of sustainability (MATSEC, 2008b). "Systems of Knowledge" has created a lot of controversy in the Maltese islands due to its being obligatory for entry to university (D'Amato, 1992), and there is still discussion to remove "Systems of Knowledge" as an obligatory entry requirement (MATSEC, 2006). However, Ventura considers that the course has increased students' awareness of the human and natural environment as the former are exposed to a number of environmental issues (Ventura, 1994). Nevertheless, it is an assumption not based on any form of research. The MATSEC review committee believes that the course helps students improve their cognitive and practical problem-solving abilities and is in line with current educational trends, emphasising pragmatic problem-solving approaches (MATSEC, 2006). Nonetheless, as students approach this examination as a hurdle, the main approach adopted by some students is to memorise facts and recycle them in examination papers.

In 1992, environmental science was introduced at the intermediate level for post-secondary students. The syllabus includes sections on the atmosphere and atmospheric pollution, water and water pollution, ecology, conservation biology, agriculture, exploitation of natural resources, solid and liquid waste disposal. This subject does not only limit itself to the science of the environment, but also has sections that specifically deal with the social and eco- 
nomic associations of the environment. The syllabus makes an effort to take a holistic view of sustainable development by combining aspects from the natural, social and economic fields. Nevertheless, most of the emphasis is on the scientific aspect of the subject, as the examination has normally been biased towards this area, presumably as scientific knowledge is easier to assess than value development.

\section{Teaching and EE}

The majority of schools, especially the government schools, advocate the 'job slots' view or a neoclassical view of education. The system tends to domesticate pupils to the teachers' demands and keeps them competing against each other for teacher and school recognition. The traditional pedagogy prevalent in the government's schools is the one in which pupils are prepared for examinations. While the pupils are merely absorbing this information to regurgitate it in the exam paper, the teacher is, here, seen as the provider of information. Unfortunately, teachers' success is also attached to the percentage pass rate of pupils in the examination. In this scenario, fieldtrips, experiential and participative pedagogy, which are much advocated by EE texts, are viewed as a waste of time. Pace (1995) argues that it is only the individual teacher's interest and concern about the environment that ensures the integration of environmental issues in daily teaching, whatever EE policy adopted.

Some teachers spend a large part of their time in drilling exercises and in working out papers with students, at the expense of value development and skill acquisition. They effectively become promoters of this educational ideology, as every statement they make in a classroom is value-laden and connected with ideas about the purpose of education and life (Lawton, 1989).

\section{The government responds: In the 1990s}

The growing concern about the blatant urban sprawl and the changing environment of the Maltese islands led to the enactment of the Environmental Protection Act in 1990 and the subsequent publication of the Malta Structure Plan (MSP), which covers a period of twenty years up to the year 2010 and is concerned with resource creation, management and protection. The MSP has more than three hundred policy statements which address sustainable development. Four policies are particularly related to EE are the following:

- actively promote educational programmes aimed at creating positive patterns of behaviour of individuals, groups and of society as a whole towards the environment;

- establish a resource centre for EE, in conjunction with the department of education and the government's environment agency, whose function will be (1) to keep the Maltese public adequately informed about environmental matters; (2) encourage and promote the establishment of field centres by recognised educational institutions and of interpretative visitor centres associated with conservation areas, pro- 
vided that these are set up in harmony with existing policies and regulations; (3) encourage and promote public and private research on the environment and on environmental problems, in conjunction with the appropriate government agencies, and to disseminate it widely (Ministry for Development of Infrastructure, 1990).

These objectives are mainly concerned with informal EE. The Maltese government seems to be well-disposed to EE in achieving environmental policy objectives, as it does fund EE projects. On closer scrutiny, however, one finds that most of these projects have short-term goals and are ideal for promoting the government's image. Lack of clear national policy on EE has resulted in a waste of human resources and the shelving of long-term EE initiatives, including the National Environmental Education Strategy (NEES) (Pace, 2002). The NEES was the outcome of the second training workshop on EE in Malta, called "In Today's Education, Tomorrow's Environment". The NEES was an attempt to develop a central infrastructure that co-ordinates EE initiatives (NEES, 1995). From the beginning, the NEES had little political support and insufficient funding. The plan was to deliver a list of guidelines and suggestions for the promotion of sustainability. The government, though, seems to prefer funding plans with short-term goals, such as cleanup campaigns (Pace, 2002).

\section{Focus on one study of local EE development}

Pace $(1995,1997)$ argues that there are three major phases in the evolution of EE initiatives in the Maltese islands:

1. awareness phase (1960s-1970s) characterised by irregular activities, mainly organised by NGOs, aimed at raising public awareness and shaping public opinion to improve the state of the Maltese environment;

2. fragmentary phase (1980s-early 1990s) characterised by the 'institutionalisation' of EE when a variety of actors assumed responsibility for EE, but failed to co-ordinate initiatives;

3. co-ordinated phase (from mid 1990s), involving the setting up of the NEES and characterised by a nation-wide co-ordinated activities and making the best use of available resources.

The first two phases are fairly straightforward and illustrate the first attempts at EE by environmental NGOs followed by the second phase of formal institutions that gather momentum in administering EE courses, most of which were more concerned with imparting environmental knowledge. The third phase is, probably, an idealistic assumption and has yet to start. Much work is still duplicated, mostly as the NEES did not receive adequate government support; consequently, the co-ordinated phase is still in its infancy (Pace, 1995). As a matter of fact, the third phase has never lifted off due to a number of reasons. Firstly, due to the change in the government, two years after the origin of the NEES, a number of government education officials were changed or transferred, and contacts and discussions had to be started again. Secondly, due to the rivalry and mutual exclusion from projects between the Faculty of Edu- 
cation of the University of Malta and the Division of Education of the Government of Malta. One explanation for this is that small states cannot offer a wide range of promotion prospects to positions of greater responsibility as these are limited in number (Farrugia, 1991). In addition, competition for scarce resources, such as status and material rewards, make collaboration rather more difficult than in larger social units.

Nevertheless, environmental activities in schools and the community have increased, particularly due to an increment in school participation in EU funded educational projects and through the work of environmental NGOs.

\section{Latest developments}

The latest developments with regard to EE in the Maltese islands are the formation of the Maltese Association of Environmental Educators (MAEE), which was formed in April 2002, the formation of the Centre for Environmental Education Research (CEER) in 2004, the launching of the Young Reporters for the Environment (YRE) programme in 2008 and the introduction of the first masters in education for sustainable development at the University of Malta in 2011. The MAEE is a non-profit organisation of teachers, students, community educators and volunteers working in the field of EE. The main goal of MAEE is to promote $\mathrm{EE}$ and support the work of environmental educators. In particular, it aims to encourage the development and dissemination of EE in Malta, to promote research in EE and disseminate its results in the educational community. It, presently, comprises about 28 members, but has never, actually, started working owing to the other pressures on the committee members. The CEER was set up in 2004 with the intention of acting as a centre of excellence for EE research in the Mediterranean. It has been promised funds and a building, but, as yet, these have not been forthcoming, mainly due to the 'bureaucratic government system' which is prevalent on the island. Nonetheless, the CEER has now managed to launch the first masters in education for sustainable development in Malta. This three-year course targets teachers and education experts and aims to provide different perspectives of sustainable development, derived from the interaction of different environmental, societal and economic concerns (CEER, 2011).

YRE, a secondary school programme run by the FEE has been launched in the Maltese islands in 2008. About eight schools have confirmed participation up till now. YRE is a continuation of the Ekoskola programme and stimulates students to become involved in environmental journalism. However, it is relatively too early to assess or analyse the effectiveness of the programme at this stage.

\section{Summary and conclusion}

EE in Malta has started off with environmental NGOs, mainly in response to the major environmental issues on the island. The awareness raising campaign was a very long affair, hindered in its development by a number of factors that contributed to the slow growth of EE in the islands. These factors include the bird hunters' NGOs, the government's non-committal 
policy, the colonial mentality and the highly competitive educational system.

In the formal education sector, one of the major problems is the dominant educational ideology that suppresses creativity and rewards rehearsed words in examinations. This ideology mostly values good marks in examinations, and, therefore, most school activities get sacrificed to make way for exam drills. Individual teachers with an interest in the environment may attempt EE in their school, but, collectively, teachers are hampered with little timetable time and lack of locally produced resources. Some materials currently used in schools were produced for use in other countries, and their transferability into the local context should be cautiously studied. EE courses at university level increase teachers' understanding, but, presently, such courses are relatively few. Environmental NGOs are doing a good job in disseminating information and creating projects, but require more funding, while the hunting NGOs are creating ambiguity.

The situation started to improve mainly in response to the requirements imposed on the country by the EU accession. The government is now realising that EE is an effective and long-term solution to ensure environmental sustainability. Many government officials speak of their commitment to sustainability, but their concern is mainly with short-term goals. The issue here is that EE goals take a long time to be achieved. This, probably, downgrades the financial backing from policy makers, as was the case with a number of programmes and initiatives, such as the NEES and the CEER. Figure 1 illustrates graphically the various factors and processes that have hindered or helped the development of EE in Malta.

All the main factors that were discovered to have had an effect on the development of EE in Malta have been incorporated into the model illustrated in Figure 1. In addition, in the pursuit of keeping the model as simple as possible, minor areas and other factors which this study identified as being of relative or minor importance were not integrated. This model is not being proposed with the assumption of being generalised to other geographical locations. It is being presented as a model for the 'particular' not for the 'general'. This line of thought is supported by Courtenay-Hall and Rogers (2002) when they state that "in sum, modelling research that aims at maximum generalizability while failing to appreciate the particularity of practical knowledge will miss much of what is significant in understanding education" (p. 287).

In the model, a number of factors have a direct influence on EE development (for instance, environmental NGOs, EU accession), other factors have a direct influence on public awareness (for instance, overt environmental issues, environmental NGOs), and one factor has been identified as having a direct influence on politics (EU accession).

The model acknowledges a direct link between the driving forces identified and local EE development; nonetheless, the effect of these factors on the actual development of EE is mediated through a number of barriers (shaded grey in the model) identified through the contextual study. These barriers appear to decrease the potential of the driving factors that facilitate EE development. They include politics, the colonial mentality, bird hunters' NGOs and the highly competitive educational system. The 'Politics' and the 'Colonial mentality' barriers are 
thought to be the main hindrances to the evolution of local EE.

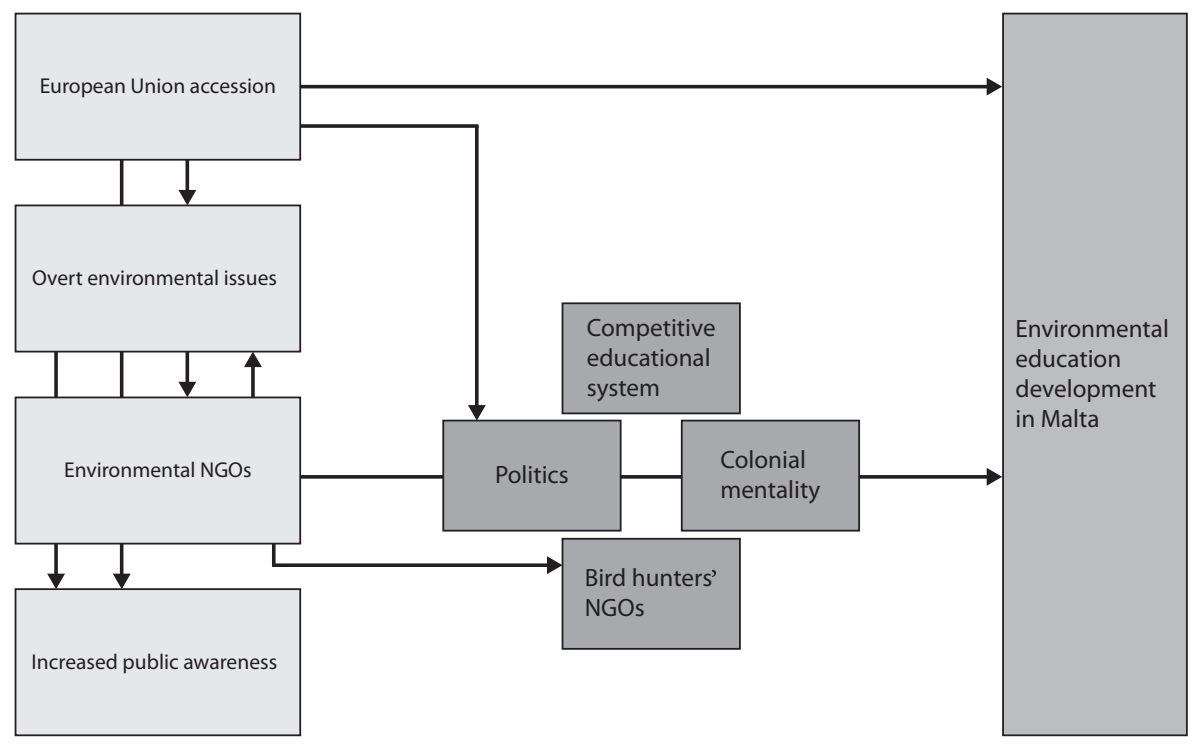

Figure 1. Driving forces and barriers in the development of environmental education in Malta

The arrows in Figure 1 indicate how the various factors influence each other and how they influence the development of EE in Malta. The model is broadly self-explanatory and depicts the complex and evolving relationship between politics, the Maltese mentality, environmental NGOs and local EE development. EU accession and public awareness have a direct link between them, but other possible indirect linkages may exist. The model acknowledges that EU accession had a direct effect on EE development and, also, influenced politics directly. This model indicates that the relation is indeed multifaceted and acknowledges the fact that EE development was also mediated and influenced by public awareness and overt environmental issues, which, in turn, were influenced by EU accession and environmental NGOs. This reciprocal dimension indicates that the model includes communal elements rather than only individualistic ones.

\section{The way forward}

The findings from this study have shed light on the effectiveness or otherwise of historical and current EE driving forces and barriers in EE development. The importance of environmental NGOs and EU accession as having a direct influence on EE development and the effect of overt environmental issues as factors that have a direct influence on public awareness have been underscored. The contextual study has also highlighted a number of important barriers that have hindered the evolution of local EE. These barriers include politics, the colonial mentality, bird hunters' NGOs and the highly competitive educational system.

Some of the barriers that are not allowing the development of EE include political con- 
cerns. These are directly related to the government, its institutions and the political parties. Political parties should actively aim to reduce the sense of futility by seeking young people's opinions through voluntary meetings, organised seminars and debates on current environmental issues, in which young people are heard and given centre stage. In the two-party game of Maltese politics, suggestions that may undermine the possibility of gaining political advantage may not be taken seriously. I believe that this is not the case here.

The main concern that has been indicated is the lack of textbooks on the Maltese environment. Rather than let authors try to make ends meet (Malta is a very limited market) and publish the books themselves (as the situation stands now), the government should actively commission authors to publish such books to fill in these lacunae.

NGOs, local policy makers and educators have to take these findings very seriously when devising new EE programmes. This is to ensure that such programmes lead to an effective positive development of EE. Researchers should start studying the effectiveness or otherwise of such programmes, so that maximum benefit is derived from the limited financial and human resources available. In this scenario, schools should be main stakeholders not only in terms of educational policies, but also in relation to environmental ones, both at the regional and national level.

Rather than fund and rely solely on NGOs to provide EE at the primary and secondary level, the government should infuse values and education for sustainability in the curriculum. This change needs to be accompanied by the actual removal of $11+$ exams which have been identified through the contextual study as the main factor that reduces the possibility of EE in the classroom. Additionally, teachers need to be well-prepared for this change, and the Faculty of Education at the University of Malta has to respond by offering a much wider variety of units to equip teachers with the necessary skills to cope with this transformation. Practicing teachers should also follow these units during in-service teacher training as part of their continuous professional development.

This research has done the groundwork for baseline indicators regarding EE development in Malta. The following areas of research have been highlighted through this study as warranting further investigation:

- comparative analyses between EE development in different countries;

- further development of the 'Driving Forces and Barriers in the Development of Environmental Education in Malta' model within other sectors of the Mediterranean region;

- the effectiveness of the current EE projects carried out by NGOs and other institutions;

- the effectiveness of various subjects and pedagogies, including environmental science, environmental studies, systems of knowledge and biology, at various school levels to bring about change in a local context.

This commitment would enable the implementation of EE programmes aimed at developing an environmental ethic that would make the Maltese people move towards a sustainable 
society. It should empower citizens to participate in decision-making and management in sustainable development, which is one of the objectives of EE.

\section{References:}

Abela, M. (2001, November 5). More members in NGOs. The Times, pp. 6-7.

Boissevain, J. (1990). Why do the Maltese ask so few questions? Education 3(4), 16-18.

Brody, M. J. (1994). Student science knowledge related to ecological crisis. International Journal of Science Education, 16(4), 421-435.

Centre for Environmental Education and Research. (2011). Masters in education for sustainable development course description. Msida: University of Malta.

Courtenay-Hall, P., \& Rogers, L. (2002). Gaps in mind: Problems in environmental knowledgebehaviour modelling research. Environmental Education Research, 8(3), 283-297.

D’Amato, C. (1992). Systems of knowledge: A case study of curriculum development. Unpublished master's thesis, University of Malta, Msida, Malta.

Darmanin, M. (1990). Maltese primary school teachers' experience of centralized policies. British Journal of Sociology of Education, 11(3), 275-308.

Farrugia, C. J. (1991). Malta: Educational development in a small island state. Prospects, 21(4), 584-594.

Farrugia, C. J. (1992). Autonomy and control in the Maltese educational system. International Review of Education, 38(2), 155-171.

Fenech, J. (1994). Managing schools in a centralized system: Headteachers at work. Educational Management and Administration, 22(2), 18-27.

Grima, D. (1996). Dinja Wahda - a case study. In P. Pace (Ed.), In Today's Education Tomorrow's Environment (pp. 69-82). Valletta: Ministry of Education.

Ham, S., \& Sewing, D. R. (1987). Barriers to environmental education. Journal of Environmental Education, 19(2), 17-24.

Lawton, D. (1989). Education, culture and the national curriculum. London: Hodder and Stoughton Publishers.

The Matriculation and Secondary Education Certificate. (2006). Strengthening a national examination system. Msida: University of Malta.

The Matriculation and Secondary Education Certificate. (2008a). Statistical report 2007. Msida: University of Malta.

The Matriculation and Secondary Education Certificate. (2008b). Systems of knowledge syllabus 2008-2010. Msida: University of Malta.

Mifsud, M. (1993). Educational resources in state secondary schools and junior lyceums. Unpublished bachelor's thesis, University of Malta, Msida, Malta. 
Mifsud, M. (2004). What are the problems of implementing environmental education in the school sector. Unpublished master's thesis, London Southbank University, London, UK.

Ministry of Education. (1989). National minimum curriculum (primary level) L.N.73, 1989. Valletta: Ministry of Education.

Ministry of Education. (1990). National minimum curriculum (Secondary Level) L.N.103, 1989. Valletta: Ministry of Education.

Ministry of Education. (1991). National minimum curriculum (Postsecondary Level), L.N.109, 1991. Valletta: Ministry of Education.

Ministry of Education. (1999). Creating the future together: National minimum curriculum. Floriana: Maltese Ministry of Education.

Ministry for Development of Infrastructure. (1990). Structure plan for the Maltese islands. Draft written statement and key diagram. Valletta: Ministry for Development of Infrastructure.

Nature Trust. (1999). Nature trust statute. Msida: Nature Trust Publications.

National Environmental Education Strategy. (1995). National environmental education strategy: Business plan. Valletta: Ministry of Education.

Pace, P. (1995). Environmental education. In Z. Murphy (Ed.), Reviewing Belgrade (pp. 1-24). Paris, France/Nairobi, Kenya: UNESCO-UNEP.

Pace, P. (1997). Environmental education in Malta: Trends and challenges. Environmental Education Research, 1(1), 69-82.

Pace, P. (2002). The role of education in promoting the sustainable use of our marine resources. Valletta: Ministry of the Environment.

Samuel, H. (1993). Impediments to implementing environmental education. Journal of Environmental Education, 25(1), 26-29

Sultana, R. G. (1999). The secondary education certificate and matriculation examinations in Malta: A case study. Geneva: International Bureau of Education.

Sussman, A. (1999). A Primer on education reform. In North American Association for Environmental Education (NAEE), Guidelines for initial teacher education in environmental education (pp. 14-16). Georgia: United States Environmental Protection Agency Publications.

Ventura, F. (1993). Science and environmental education at the primary level in Malta: Separate interests, different roles. International Journal of Science Education, 15(1), 509519.

Ventura, F. (1994). Environmental education - the Malta experience. In W. L. Filho (Ed.) Environmental education in small island developing states (pp. 15-32). Vancouver: The Commonwealth of Learning.

Wain, K. (1991). The national minimum curriculum: A critical evaluation. Msida: Mireva Publishers. 
Wain, K. (1995). Tomorrow's schools: Developing effective learning cultures. Valletta: Education Division.

\section{Correspondence:}

Dr Mark Mifsud, Environmental Science Department, Junior College, University of Malta, Msida MSD 1252, Malta. Email: mark.c.mifsud@um.edu.mt 